\title{
Novel etching protocol for epidote fission tracks
}

\author{
Wagner Massayuki Nakasuga ${ }^{\mathrm{a}, \mathrm{c}, *}$, Carlos Alberto Tello Saenz ${ }^{\mathrm{a}}$, Eduardo Augusto Campos Curvo ${ }^{\mathrm{b}}$, \\ Julio Cesar Hadler Neto ${ }^{c}$, Sandro Guedes ${ }^{c}$, Rosana Silveira Resende ${ }^{a}$ \\ a Department of Physics, Chemistry and Biology, São Paulo State University, UNESP, 19060, Presidente Prudente City, SP, Brazil \\ ${ }^{\mathrm{b}}$ Institute of Physics, Federal University of Mato Grosso, UFMT, 78060-900, Cuiabá City, MT, Brazil \\ "Institute of Physics "Gleb Wataghin", University of Campinas, 13083-859, Campinas City, SP, Brazil
}

A R T I C L E IN F O

\section{Keywords:}

Epidote

Clinozoisite

Etching

\begin{abstract}
A B S T R A C T
Along the years, etching for fission tracks was a major issue in the development of the epidote fission track dating. It was not a consensus in the scientific community. As an attempt to mitigate it, we present a novel etching protocol ( $\mathrm{HF} 40 \%$ at $15^{\circ} \mathrm{C}$ for $80 \mathrm{~min}$ ) and test it in ten different natural samples etched with $\mathrm{HF} 40 \%$ at $15^{\circ} \mathrm{C}$ for $80 \mathrm{~min}$ (nine epidotes and one clinozoisite). The samples had their chemical compositions determined, forming a database for epidote chemical compositions. Fission tracks were observed in five samples. The uranium content in the remaining four samples was too low and hence tracks could not be observed. Further analyses, Raman and uranium concentration, confirm this observation. Fission tracks were not observed in clinozoisite sample. The proposed etching protocol showed to be less hazardous and efficient to etching fission tracks in epidote.
\end{abstract}

\section{Introduction}

There are three processes leading to epidote formation (Bar et al., 1974): deuteric action during the late phase of magmatic crystallization, low-grade regional metamorphism and hydrothermal activity. When the temperature of formation is below the closure temperature for fission track system in epidote, the age of magmatic crystallization, low-grade regional metamorphism, formation or reactivation of geological faults may potentially be obtained by epidote fission track dating (FTD). Epidote was one of the target mineral investigated in the early years of fission track dating (for instance, Naeser et al., 1970, Bar et al., 1974, Haack, 1976). Between 1970 and 1983 several etching procedures were proposed for the revelation of fission tracks in epidote (Table 1). Initially, epidote fission tracks were etched with hot sodium hydroxide $(\mathrm{NaOH})$ in several controlled conditions. Bal et al. (1982) used $48 \%$ hydrofluoric acid (HF) at $40{ }^{\circ} \mathrm{C}$ for various times. Chakranarayan and Powar (1982) revealed epidote fission tracks with $\mathrm{NaOH}$ followed by HF etching. Lal and Waraich (1983) proposed a combination of $\mathrm{HF}$ and $\mathrm{HCl}$ at $25^{\circ} \mathrm{C}$. The disagreement among laboratories on a standard etching condition led to the discontinuance of the epidote fission track studies in the mid-eighties. Two decades later, Curvo et al. (2005) resumed the efforts to set chemical etching conditions. After failing to reveal fission tracks in epidote on a Brazilian sample using $25 \mathrm{~N} \mathrm{NaOH}$, for $100 \mathrm{~min}$ at $75^{\circ} \mathrm{C}$ they succeeded employing $48 \% \mathrm{HF}$ for $12.5 \mathrm{~min}$ at $35^{\circ} \mathrm{C}$. This latter condition proved to effective in etching fission tracks, however, the high concentration of the etchant as well the relatively elevated temperature at which the chemical treatment is carried out, makes this procedure more laborious and potentially unhealthy.

Based on Curvo et al. (2005) findings, we propose a safer and more effective chemical etching for the epidote fission track. A set of 10 epidote samples (8 samples from Brazil and 2 samples from Peru) were characterized in detail by energy dispersive $\mathrm{x}$-ray spectroscopy (SEMEDS), to obtain the concentrations of major elements and then they are tested for the proposed etching.

\section{Sample}

All samples were donated by fellow researchers (CLI, BD485, BD495/2, N336/2, Brejui, P and EV) or purchased (Diamantina, Capelinha and EQ). Samples CLI to Brejuí, are originally from Rio Grande do Norte State, NE-Brazil, whereas samples P and EV came from Peru. Epidote samples from Diamantina and Capelinha are named after their cities of origin in Minas Gerais State, SE-Brazil. The geographical location of the EQ is unknown.

The samples are in two forms: $\sim 0.5 \mathrm{~mm}$ grains size and $3 \mathrm{~cm} \times 2 \mathrm{~cm}$ phenocrysts dimension.

\footnotetext{
* Corresponding author. Department of Physics, Chemistry and Biology, São Paulo State University, UNESP, 19060, Presidente Prudente City, SP, Brazil.

E-mail addresses: wamassa@gmail.com, nakasuga@ifi.unicamp.br (W.M. Nakasuga).
} 
Table 1

Summary of several etching protocols used for epidote fission-track dating over the years.

\begin{tabular}{ll}
\hline Author & Etching conditions \\
\hline Naeser et al., 1970 & $50 \mathrm{~N} \mathrm{NaOH}, 150{ }^{\circ} \mathrm{C}$, for $60-180 \mathrm{~min}$ \\
Bar et al., 1974 & $37.5 \mathrm{~N} \mathrm{NaOH}, 159^{\circ} \mathrm{C}$ for $150 \mathrm{~min}$ \\
Haack 1976 & $75 \mathrm{~N} \mathrm{NaOH}$, boiling for $30 \mathrm{~min}$ \\
Saini et al., 1978 & $100 \mathrm{~N} \mathrm{NaOH}, 200^{\circ} \mathrm{C}$ for $40 \mathrm{~min}$ \\
Bal et al., 1982 & $48 \% \mathrm{HF}, 40^{\circ} \mathrm{C}$ for different times \\
Chakranarayan and Powar, & $25 \mathrm{~N} \mathrm{NaOH}, 150{ }^{\circ} \mathrm{C}$ for 120 min $+48 \% \mathrm{HF}$, \\
$\quad 382$ & $30{ }^{\circ} \mathrm{C}$ for 15 min \\
Lal and Waraich, 1983 & $\mathrm{HF}: \mathrm{HCl}(1: 1), 25^{\circ} \mathrm{C}$, for $20-25 \mathrm{~min}$ \\
Curvo et al., 2005 & $\mathrm{HF} 48 \%, 35^{\circ} \mathrm{C}$ for 12.5 min \\
\hline
\end{tabular}

\section{Experimental procedure}

\subsection{Step-etching experiments}

To build a step-etch curve, we chose the epidote phenocryst from the Brejuí Scheelite Mine, located in the Borborema Province, Rio Grande do Norte State-NE, Brazil. This is a well-known sample and has already been used in a previous etching study and dated with the FTD (Curvo et al., 2005).

A piece of the Brejuí sample was broken into smaller parts of $\sim 1 \mathrm{~mm}$ in diameter. The grains were mounted in epoxy resin, polished and etched. The etching parameters were chosen to make chemical treatment less hazardous than the one proposed by Curvo et al. (2005): $40 \% \mathrm{HF}$ at $15 \pm 1{ }^{\circ} \mathrm{C}$. The solution was placed in a circulating water bath in which the temperature is constant and controlled within $\pm 1{ }^{\circ} \mathrm{C}$. The track density and confined tracks parallel to the surface were measured under a regular microscope, with a nominal magnification of $1000 \times(100 \times$ dry objective and $10 \times$ ocular lenses $)$.

The step-etch curve was built with etching times of $30,40,50,60$, $70,80,90,100$ and $110 \mathrm{~min}$. A different mount ( $\sim 100$ grains each) was used in each experiment. Fossil confined fission track lengths and fossil fission track densities were measured in all mounts.

\subsection{Sample characterization}

The sample chemical compositions were determined by SEM-EDS. The equipment used was a SEM model LEO 430i coupled with an EDS system. The equipment settings were: $108 \mathrm{eV}, 15 \mathrm{kV}$ accelerating voltage, $19 \mathrm{~mm}$ working distance, $3 \mathrm{nA}$ beam current, and vacuum of $1 \times 10^{-5}$ Torr.

The Raman spectra were recorded using a micro-Raman spectrograph Renishaw model in-Via equipped with a Leica microscope model DMLM and couple with an air-cooled CCD detector. Single-point spectra were recorded with $633 \mathrm{~nm}$ helium-neon laser line with 10s accumulation time and 1800 grooves/mm grating.

\subsection{Etching experiments}

A total of ten epidote samples were analyzed. From those, five were phenocrysts and five were composed of grains. The phenocrysts were sliced in $\sim 1 \mathrm{~mm}$ thick slices and the grains were hand-picked under a stereomicroscope. Each sample was mounted in epoxy resin, grounded with sandpaper, polished with diamond suspension and etched with $40 \% \mathrm{HF}$ at $15 \pm 1{ }^{\circ} \mathrm{C}$ for $80 \mathrm{~min}$, which was the etching time selected for the step-etch experiments (see Section 4.2).

\subsection{Uranium content determination}

After the etching procedure, we could not find tracks in five samples (CLI, EV, Diamantina, Capelinha and EQ). This could be either because of variations in the chemical composition, that could imply in different etching responses, or just because uranium content was too low. To check the latter possibility, these samples were sent to the nuclear reactor with a muscovite mica juxtaposed to them. Irradiation was performed with a nominal thermal neutron fluence of $3 \times 10^{15}$ neutrons/ $\mathrm{cm}^{2}$ at the IPEN/CNEN reactor, Brazil. To estimate the ${ }^{238} \mathrm{U}$ concentration in $\mu \mathrm{g} / \mathrm{g}$, the equation relating the induced fission track density, $\rho_{i}$, with the thermal neutron fluence was applied (Wagner and Van den haute, 1992):

$\rho_{i}=g N_{235} R_{i}(\eta q)_{i} \sigma \phi$

where $g$ is the geometry factor, $N_{235}$ is the number of ${ }^{235} \mathrm{U}$ atoms per unit of volume, $R_{i}$ is the mean length of etched fission tracks in the muscovite mica, $(\eta q)_{i}$ is the efficiency of the etching and observation under optical microscopy (Jonckheere and Van den haute, 1999), $\sigma$ is the cross section for fission of ${ }^{235} U$ by thermal neutron capture and $\Phi$ is the thermal neutron fluence.

The geometry factor, $g$, of the pre-etched sample surface is 0.5 for an external surface (Wagner and Van den haute, 1992). We adopted the value of $20.50 \pm 0.25 \mu \mathrm{m}$ for $R_{i}$ (Jonckheere, 2003). According to Soares et al. (2013) the $(\eta q)_{i}$ parameter is $0.92 \pm 0.02$ and $\sigma$ is 584.33 b (Carlson, 2011).

The number of ${ }^{238} \mathrm{U}$ atoms per unit of volume, $N_{238}$, can be regarded to the natural abundance of ${ }^{238} \mathrm{U} /{ }^{235} \mathrm{U}(\sim 137.88)$ by (Steiger and Jäger, 1977):

$N_{238}=N_{235} \cdot 137.88$

The uranium content can be estimated by (Hasebe et al., 2004):

$238 U=\frac{N_{238} \cdot M}{N_{A} \cdot 10^{-6} \cdot d}$

where ${ }^{238} U$ is given in $(\mu \mathrm{g} / \mathrm{g}), N_{A}$ is the Avogadro's number, $M$ is the molar mass of ${ }^{238} U$ and $d$ is the muscovite mica density.

\section{Results and discussion}

\subsection{Chemical characterization}

A database of chemical compositions for 10 epidotes samples was built. The major element contents, determined by SEM-EDS, are shown in Table 2. Only one sample, CLI, turned out not to be epidote. The lack of iron in its chemical composition indicates that CLI is a clinozoite.

\subsection{Step-etch experiments}

Photomicrographs of tracks in various stages of etching (30-110 $\mathrm{min}$ at $40 \% \mathrm{HF}$ at $15 \pm 1{ }^{\circ} \mathrm{C}$ ) are shown in Fig. 1. Visually, some tracks etched for $30,40,50$ and 60 min are very thin showing an under-etch of the tracks. For $110 \mathrm{~min}$, tracks are very thick, making more difficult distinguish individual tracks due to track overlapping. Tracks at 70, 80 and $90 \mathrm{~min}$ are comfortably distinguished. They are not

Table 2

Chemical composition ( $w t \%$ ) obtained through SEM-EDS. Nine samples are epidotes and one (CLI) is a clinozoisite. The Brejuí sample, in bold, has been used in other works (Curvo et al., 2005) and is used as our reference sample.

\begin{tabular}{lllllllll}
\hline Samples & $\mathrm{C}$ & $\mathrm{Al}$ & $\mathrm{Si}$ & $\mathrm{Ca}$ & $\mathrm{Fe}$ & $\mathrm{O}$ & $\mathrm{Cr}$ & $\mathrm{Mn}$ \\
\hline CLI & 10.27 & 9.99 & 12.68 & 10.96 & 0.02 & 55.15 & 0.02 & 0.01 \\
BD485-1 & 9.97 & 7.46 & 12.62 & 9.41 & 4.07 & 53.63 & 0.02 & 0.08 \\
BD495-2 & 9.13 & 8.72 & 12.43 & 11.32 & 5.92 & 52.47 & - & - \\
N336-2 & 9.54 & 7.83 & 13.80 & 9.94 & 4.36 & 53.77 & 0.02 & 0.03 \\
P & 9.97 & 7.29 & 16.29 & 6.24 & 3.67 & 56.03 & 0.02 & 0.05 \\
Brejuí & $\mathbf{9 . 6 8}$ & $\mathbf{8 . 1 6}$ & $\mathbf{1 1 . 9 3}$ & $\mathbf{1 0 . 8 5}$ & $\mathbf{6 . 3 6}$ & $\mathbf{5 2 . 8 4}$ & $\mathbf{0 . 0 5}$ & $\mathbf{0 . 1 3}$ \\
Diamantina & 9.93 & 8.09 & 11.83 & 10.76 & 6.08 & 53.21 & 0.01 & 0.06 \\
Capelinha & 9.34 & 8.65 & 12.30 & 11.11 & 5.77 & 52.73 & 0.02 & 0.04 \\
EQ & 9.49 & 7.82 & 12.07 & 10.94 & 7.16 & 52.44 & 0.01 & 0.05 \\
EV & 9.34 & 9.58 & 12.40 & 11.19 & 4.20 & 53.24 & 0.02 & 0.02 \\
\hline
\end{tabular}



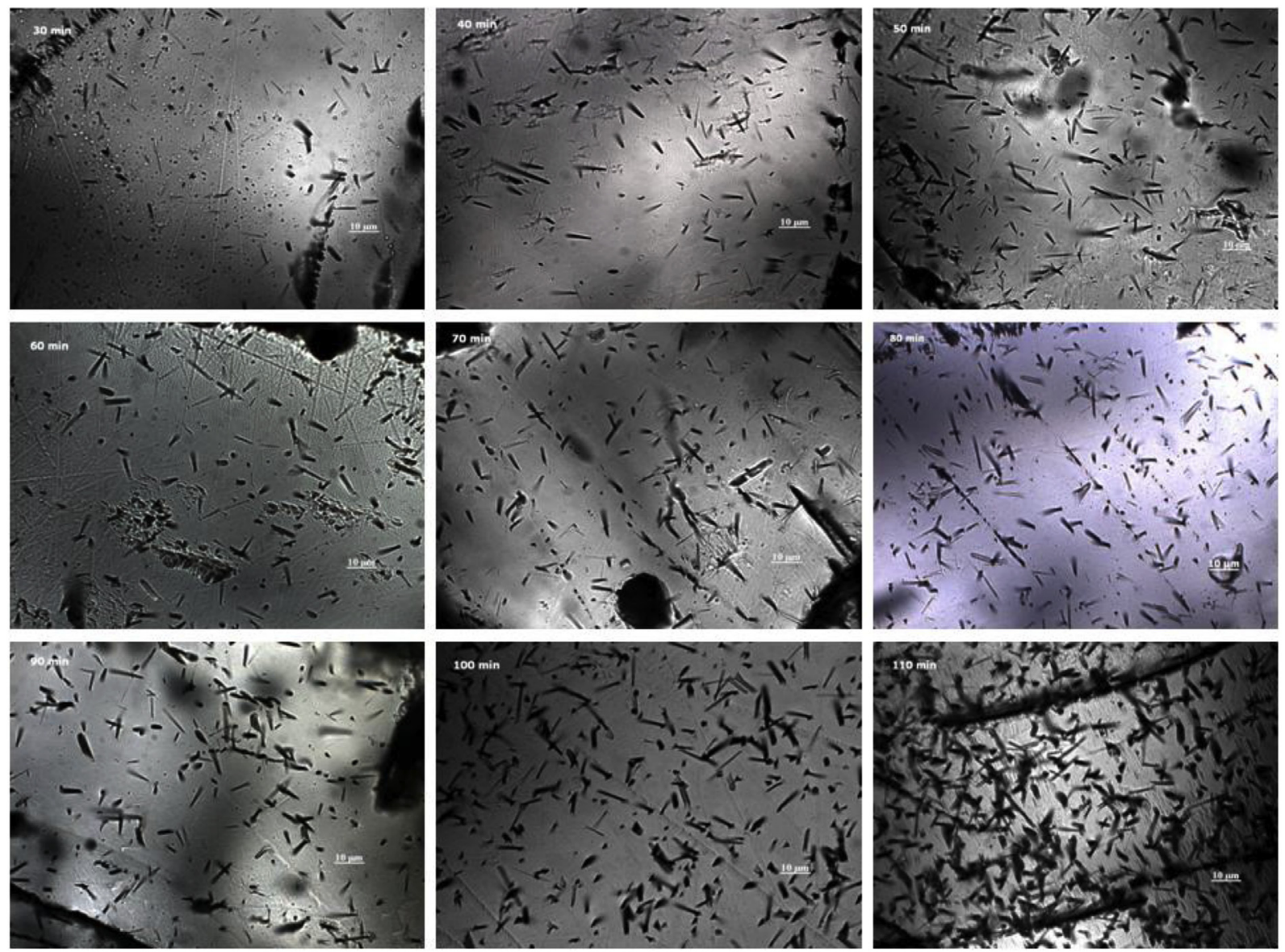

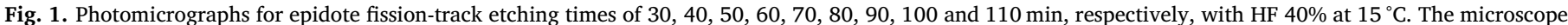
magnification used was $1000 \times$.

Table 3

Data for the step-etch curves of fission track densities and lengths for different etching times.

\begin{tabular}{llllll}
\hline $\begin{array}{l}\text { Time } \\
\text { (minutes) }\end{array}$ & $\mathrm{N}$ & $\mathrm{x}$ & $\begin{array}{l}\text { Track density }\left(\times 10^{6}\right. \\
\left.\text { tracks } / \mathrm{cm}^{2}\right)\end{array}$ & $\mathrm{N}_{\mathrm{c}}$ & $\mathrm{L}(\mu \mathrm{m})$ \\
\hline $\mathbf{3 0}$ & 100 & 591 & $0.66 \pm 0.03$ & 23 & $9.15 \pm 0.51$ \\
$\mathbf{4 0}$ & 100 & 889 & $0.99 \pm 0.03$ & 32 & $9.87 \pm 0.44$ \\
$\mathbf{5 0}$ & 100 & 1221 & $1.36 \pm 0.04$ & 52 & $9.76 \pm 0.30$ \\
$\mathbf{6 0}$ & 100 & 1247 & $1.39 \pm 0.04$ & 65 & $10.98 \pm 0.25$ \\
$\mathbf{7 0}$ & 100 & 1584 & $1.76 \pm 0.04$ & 100 & $11.73 \pm 0.19$ \\
$\mathbf{8 0}$ & 100 & 1671 & $1.86 \pm 0.05$ & 101 & $11.53 \pm 0.18$ \\
$\mathbf{9 0}$ & 100 & 1812 & $2.01 \pm 0.05$ & 104 & $11.67 \pm 0.16$ \\
$\mathbf{1 0 0}$ & 100 & 1854 & $2.06 \pm 0.05$ & 100 & $11.68 \pm 0.18$ \\
$\mathbf{1 1 0}$ & 100 & 1670 & $1.86 \pm 0.05$ & 100 & $12.29 \pm 0.20$ \\
\hline
\end{tabular}

$\mathrm{N}$ : fields counted; $\mathrm{x}$ : number of tracks; $\mathrm{N}_{c}$; number of measured confined tracks and L: mean confined tracks length. The error related means the standard deviation of the mean $(1 \sigma)$.

so thin, neither so thick. The results of the step-etch experiments are shown in Table 3. The step-etch curves for fission track densities and lengths are shown in Fig. 2. Track-in-tracks and track-in-cleavage confined fission tracks were measured to determine the mean confined track lengths.

The definition of optimal time of the fission track density step-etch curve for fission track densities (Figure 2A) demands some consideration, since the etching time at which track density stop growing is uncertain. In addition, at $110 \mathrm{~min}$, track overlap start affecting the counting efficiency as it is shown in Fig. 1. Track length, however, seems to stop increasing from 70 min etching time (Figure 2B). Pulling together the above information, we can situate the optimal etching time between 70 and $100 \mathrm{~min}$. In principle, any of these preselected etching times could be adopted. The last criterion applied was the ease of counting, which lead us to choose $80 \mathrm{~min}$.

\subsection{Etching experiments and analysis}

The remaining nine samples were etched with the chosen conditions (HF $40 \%$ at $15 \pm 1{ }^{\circ} \mathrm{C}$ for $80 \mathrm{~min}$ ). Only four of them fission tracks were observed (four grain samples): BD485, BD495/2, N336/2 and P. Photomicrographs of the etched tracks in these samples are shown in Fig. 3. The samples CLI, Diamantina, Capelinha, EQ and EV did not show fission tracks. All of them are phenocrysts, except the CLI, as commented above. Although the CLI is not an epidote it is part of epidote group and was prepared and etched together with the other samples.

Chemical compositions (Table 2) indicate that the phenocrysts are epidote. There are no significant differences in chemical compositions among samples, including Brejuí. In addition, the Raman spectra of these samples were compared to the Brejuí epidote Raman spectrum (Fig. 4). All spectra have the peaks at the same Raman shifts of Brejuí. Differences in peak intensity appear because we did not find the way to analyze the samples at the exact same crystallographic orientation, due to difficult to manipulate a monoclinic mineral with many crystallographic faces. Thus, we can conclude that chemical composition was not the cause we did not find tracks in these samples.

The muscovite micas juxtaposed with the epidote phenocrysts samples (EV, Diamantina, Capelinha and EQ) during thermal neutron irradiation presented lower surface fission track densities $\left(\sim 10^{4} \mathrm{~cm}^{-2}\right.$, Table 4) when compared with the Brejuí sample irradiated with similar 

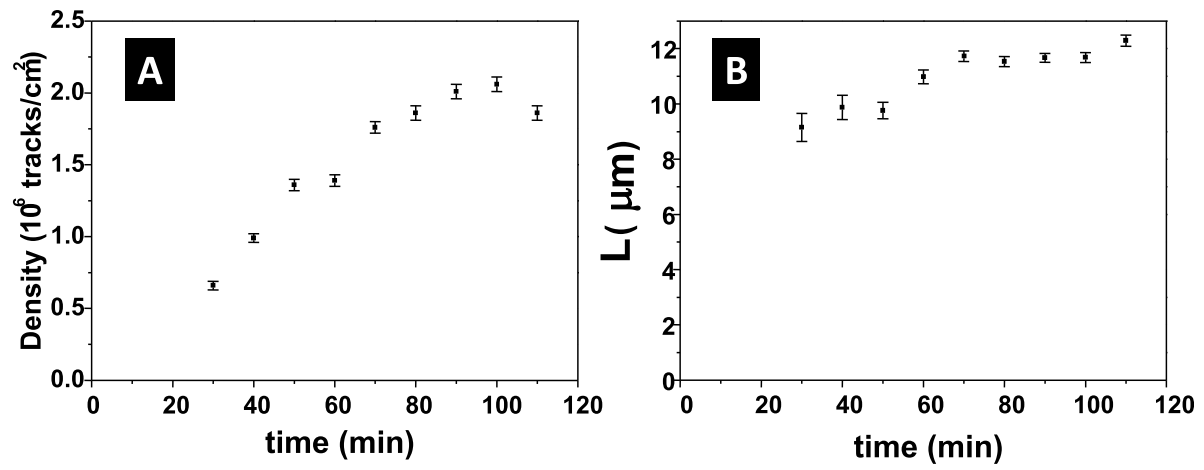

Fig. 2. Etching curve: A) Fission-track density and B) Confined fission-track length.

neutron fluence $\left(\sim 10^{6} \mathrm{~cm}^{-2}\right.$, Curvo et al., 2007). According to Nakasuga (2010), the uranium content of Brejuí sample is $10 \mu \mathrm{g} / \mathrm{g}$ and Curvo et al. (2007) found a track density of $\sim 10^{6}$ tracks $/ \mathrm{cm}^{2}$ when Brejuí was irradiated with a fluence of $1.95 \times 10^{15}$ neutrons $/ \mathrm{cm}^{2}$ (approximately the same neutron fluence used in this work). Only for the sake of discussion, the ${ }^{238} \mathrm{U}$ content in these samples was estimated using equations (1), 2 and 3 . The results are shown in Table 4. In addition to the small number of counted tracks, a major source of uncertainty is the value of the neutron fluence. The nominal value was used for calculation. Our experience with this reactor, shows that the actual value is frequently about $30 \%$ lower than the nominal one. In this way, the presented ${ }^{238} \mathrm{U}$ concentration values are rough, probably underestimated values. The valuable information, however, is that the uranium concentrations in these samples are below $1 \mu \mathrm{g} / \mathrm{g}$, too low to yield a significant number of fossil fission tracks, even in a period of millions of years.

It was difficult to polish the CLI and P samples. The CLI sample is opaque, making the observation by optical microscope impossible in the transmitted light mode. At the polishing step, both samples were fragmented and after etching were totally (CLI) or partially (P) destroyed. However, as shown in Fig. 3, the P sample revealed fission tracks. These two samples are the ones that showed a greater divergent chemical composition compared with other samples of epidote (Table 2).

\section{Conclusion}

We set a new etching protocol ( $\mathrm{HF} 40 \%$ at $15^{\circ} \mathrm{C}$ for $80 \mathrm{~min}$ ) and tested it in ten samples, whose chemical compositions were determined by SEM-EDS. Nine of them were epidote and one turned out to be a

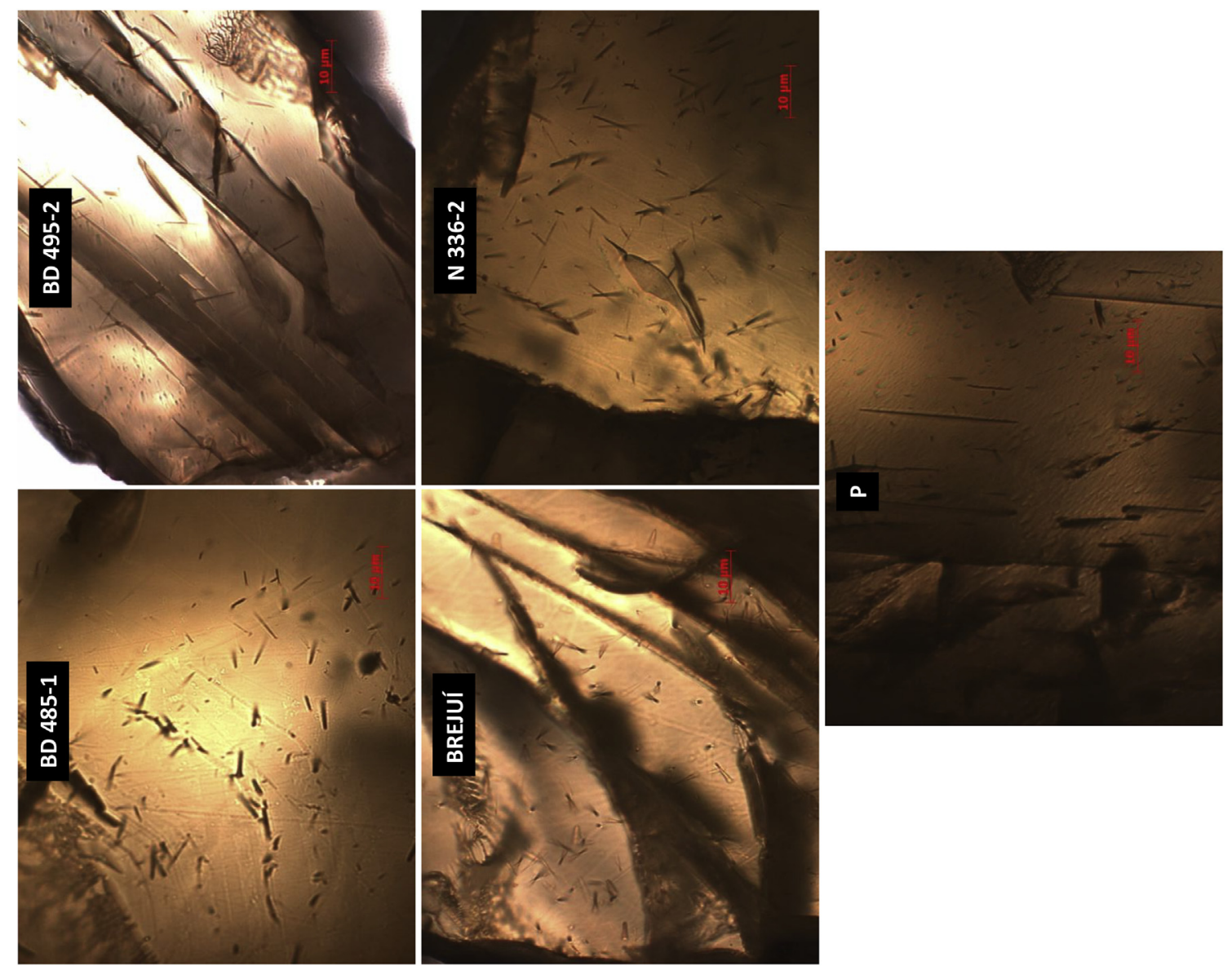

Fig. 3. Photomicrography of epidotes samples that revealed fission tracks using $\mathrm{HF} 40 \%, 15^{\circ} \mathrm{C}$ for 80 min. The microscope magnification used was $1000 \times$. 

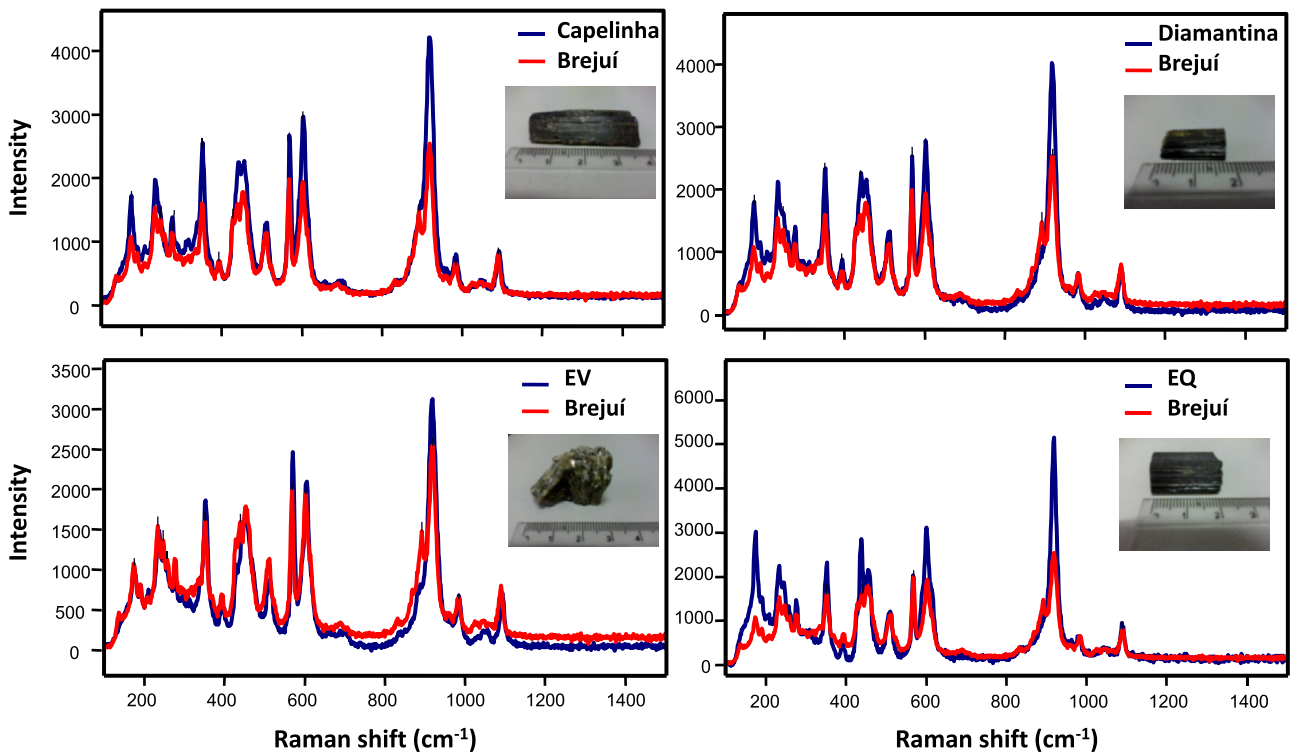

Fig. 4. Raman spectra of epidote samples. The blue line is the Brejuí sample, this one was used as a standard epidote and the red line are Capelinha, Diamantina, EV and EQ epidote samples. Photos of each epidote phenocrystal are presented in the insets. (For interpretation of the references to colour in this figure legend, the reader is referred to the Web version of this article.)
Table 4

Data for estimative of uranium concentration in some samples. The ${ }^{238} \mathrm{U}$ column is the estimative of uranium concentration in $\mu \mathrm{g} / \mathrm{g}$ of the samples.

\begin{tabular}{lllll}
\hline & $\mathrm{N}$ & $\Sigma$ tracks & $\begin{array}{l}\text { Induced density }\left(\times 10^{4} \text { tracks }\right. \\
\left.\mathrm{cm}^{2}\right)\end{array}$ & ${ }^{238} \mathrm{U}(\mu \mathrm{g} / \mathrm{g})$ \\
\hline EV & 25 & 17 & $4.3 \pm 1.0$ & $0.52 \pm 0,20$ \\
Diamantina & 25 & 9 & $2.3 \pm 0.8$ & $0.28 \pm 0.13$ \\
Capelinha & 25 & 3 & $0.8 \pm 0.5$ & $0.10 \pm 0,07$ \\
EQ & 25 & 7 & $1.8 \pm 0.7$ & $0.22 \pm 0,11$ \\
\hline
\end{tabular}

$\mathrm{N}$ is the number of analyzed fields. The errors related to Induced density means the standard deviation of the distribution $(1 \sigma)$.

clinozoisite. We could not observe tracks in the clinozoisite and four of the epidote samples. Further analyses, Raman and estimative of uranium concentration, indicate that the low uranium content is the primary cause of failing observing tracks in these epidote samples.

The proposed protocol is less hazardous than a previous one (Curvo et al., 2005) and showed to be efficient for revealing tracks. As a secondary outcome, a database of epidote chemical compositions was initiated and can be valuable information for researchers working with epidote FTD.

\section{Acknowledgements}

We are grateful to São Paulo Research Foundation (FAPESP) by financial support through grant: 2010/20496-2 and Coordination for the Improvement of Higher Education Personnel (CAPES). We are also grateful to researchers who provided us with epidote samples: Prof. Maria Helena Bezerra Maia de Hollanda, MSc. Victor Lipas Salas and MSc. Pedro Figueroa. At last, we are grateful for the reviewers' advice for this work.

\section{References}

Bal, K.D., Lal, N., Nagpaul, K.K., 1982. Fission track etching studies of different planes of epidote. Phys. Chem. Miner. 8, 158-160.

Bar, M., Kolodny, Y., Bentor, Y.K., 1974. Dating faults by fission track dating of epidotes an attempt. Earth Planet Sci. Lett. 22, 157-162.

Carlson, A.D., 2011. The neutron cross section standards, evaluations and applications. Metro 48, S328-S345.

Chakranarayan, A.B., Powar, K.B., 1982. A new etching technique for developing fission tracks in epidote. Nucl. Tracks 6 (4), 193-195.

Curvo, E.A.C., Hadler, N.J.C., Iunes, P.J., Guedes, S., Tello, S.C.A., Paulo, S.R., Hackspacher, P.C., Palissari, R., Moreira, P.A.F.P., 2005. On epidote fission track dating. Radiat. Meas. 39, 641-645.

Curvo, E.A.C., Iunes, P.J., Guedes, S., Palissari, R., Hadler, J.C., 2007. Comparison of population and external detector method dating in epidote. Radiat. Meas. 42 1307-1314.

Haack, U., 1976. The stability of fission tracks in epidote and vesuvianite. Earth Planet Sci. Lett. 127, 143-155.

Hasebe, N., Barbaran, J., Jarvis, K., Carter, A., Hurford, A.J., 2004. Apatite fission-track chonometry using laser abltion ICP-MS. Chem. Geol. 207, 135-145.

Jonckheere, R., Van den haute, P., 1999. On the frequency distributions per unit area of the projected and etchable lengths of surface-intersecting fission tracks: influences of track revelation, observation and measurement. Radiat. Meas. 30, 155-179.

Jonckheere, R., 2003. On the densities of etchable fission tracks in a mineral and coirradiated external detector with reference to fission-track dating of minerals. Chem. Geol. 200, 41-58.

Lal, N., Waraich, R.S., 1983. Comments on the paper "A new etching technique for developing fission tracks in epidote". Nucl. Tracks 7 (4), 191.

Naeser, C.W., Engels, J.C., Dodge, F.C., 1970. Fission track annealing and age determination of epidote minerals. J. Geophys. Res. 75 (8), 1579-1584.

Nakasuga, 2010. Estudo do annealing de traços de fissão em epídoto. Dissertation. Universidade Estadual Paulista - UNESP In portuguese.

Saini, H.S., Sharma, O.P., Parshad, R., Nagpaul, K.,K., 1978. Fission track annealing characteristics of epidote: applications to geochronology and geology. Nucl. Track Detect. $2,133-140$.

Soares, C.J., Guedes, S., Tello, C.A., Lixandrão Filho, A.L., Osório, A.M., Alencar, I., Dias, A.N.C., Hadler, J., 2013. Further investigation of the initial fission-track length and geometry factor in apatite fission-track thermochronology. Am. Mineral. 98, 1381-1392.

Steiger, R.H., Jäger, E., 1977. Subcomission on geochrnology: convention on the use of decay constants in geo and cosmochronology. Earth Planet Sci. Lett. 36, 359-362.

Wagner, G.A., Van den haute, P., 1992. Fission-track dating. Solid Earth Sciences Library, vol. 6. Kluwer Academic Publishers, pp. 285. 